\title{
Forest damage and snow avalanche flow regime
}

\author{
T. Feistl ${ }^{1,2}$, P. Bebi ${ }^{1}$, M. Christen ${ }^{1}$, S. Margreth ${ }^{1}$, L. Diefenbach ${ }^{3}$, and P. Bartelt ${ }^{1}$ \\ ${ }^{1}$ WSL Institute for Snow and Avalanche Research SLF, Flüelastrasse 11, 7260 Davos Dorf, Switzerland \\ ${ }^{2}$ Technical University Munich (TUM), Engineering Geology, Arcisstrasse 21, 80333 Munich, Germany \\ ${ }^{3}$ Swiss Federal Institute of Technology (ETH), Rämistrasse 101, 8092 Zurich, Switzerland
}

Correspondence to: T. Feistl (thomas.feistl@ slf.ch)

Received: 08 December 2014 - Published in Nat. Hazards Earth Syst. Sci. Discuss.: 20 January 2015

Accepted: 10 May 2015 - Published: 18 June 2015

\begin{abstract}
Snow avalanches break, uproot and overturn trees causing damage to forests. The extent of forest damage provides useful information on avalanche frequency and intensity. However, impact forces depend on avalanche flow regime. In this paper, we define avalanche loading cases representing four different avalanche flow regimes: powder, intermittent, dry and wet. Using a numerical model that simulates both powder and wet snow avalanches, we study documented events with forest damage. First we show that in the powder regime, although the applied impact pressures can be small, large bending moments in the tree stem can be produced due to the torque action of the blast. The impact area of the blast extends over the entire tree crown. We find that, powder clouds with velocities over $20 \mathrm{~m} \mathrm{~s}^{-1}$ can break tree stems. Second we demonstrate that intermittent granular loadings are equivalent to low-density uniform dry snow loadings under the assumption of homogeneous particle distributions. The intermittent regime seldom controls tree breakage. Third we calculate quasi-static pressures of wet snow avalanches and show that they can be much higher than pressures calculated using dynamic pressure formulas. Wet snow pressure depends both on avalanche volume and terrain features upstream of the tree.
\end{abstract}

\section{Introduction}

Forest damage caused by avalanches reveals the complex and variable nature of avalanche flow. Avalanches cut through forests leaving paths of broken and fractured tree stems, overturned root plates and torn branches (de Quervain, 1978; Bartelt and Stöckli, 2001) (Fig. 1). Forest destruction provides not only important information concern- ing the avalanche frequency but also the spatial extent of avalanche impact pressure. This information helps hazard engineers construct impact scenarios for different avalanche release conditions. More importantly, the capacity of mountain forests to decelerate and stop avalanches requires distinguishing between when the avalanche destroys the forest and when trees can withstand the avalanche impact pressure. Impact pressures, however, are related to avalanche flow regime (Faug et al., 2010; Sovilla et al., 2014; Vera et al., 2015). Both fast-moving dry avalanches and slow moving wet snow flows can lead to widespread forest destruction. Powder clouds can also cause extensive tree blowdowns. In this paper we relate forest damage to different avalanche flow regimes with the goal of quantifying the protective capacity of mountain forests.

The protective capacity of forests depends on the ability of trees and tree clusters to survive avalanche loading. Forests can stop small and frequent avalanches because the trees are not destroyed (Teich et al., 2012). Small avalanches cannot generate significant impact pressures to break and uproot trees. In this case, trees serve as rigid obstacles which cause snow to decelerate. Snow mass is stopped behind dense tree clusters and is subsequently removed from the avalanche (Feistl et al., 2014b). The avalanche starves. The protective capacity of the forest is thus related to the stem density and forest structure (Teich et al., 2014). If the trees break, they can no longer serve as rigid obstacles and other physical processes, such as entrainment of woody debris and root plates, slow the avalanche down (Bartelt and Stöckli, 2001). The effect of tree breaking can be parameterized by increasing the velocity-dependent turbulent friction (Christen et al., 2010a). Thus, to determine the protective capacity of forests requires an understanding of when trees serve as rigid obstacles and 


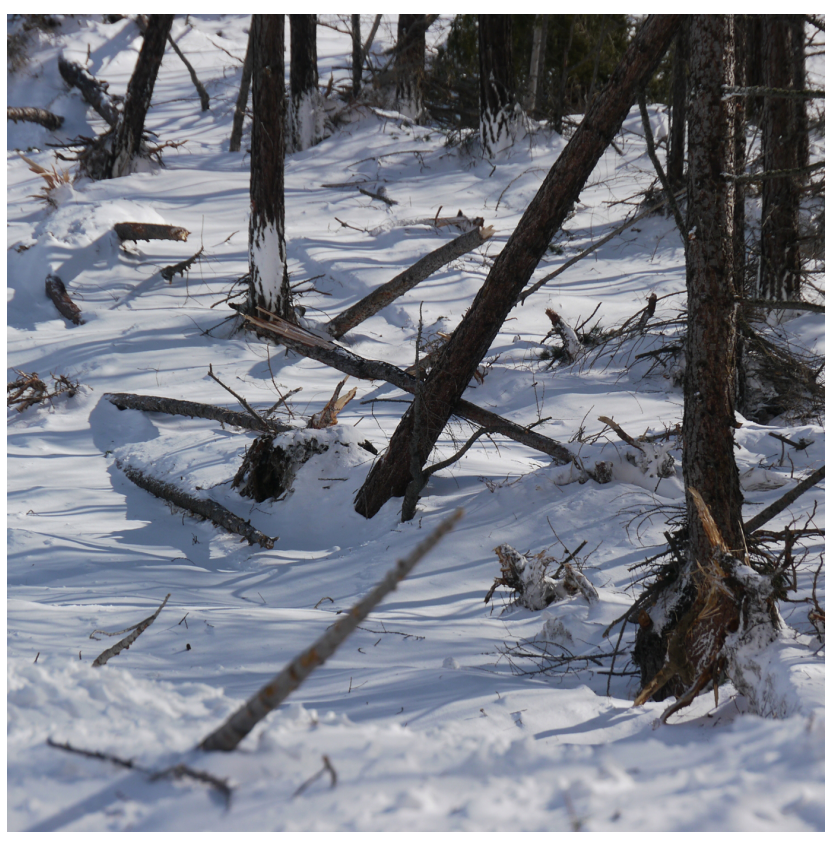

Figure 1. Destroyed and surviving trees after avalanche impact in Täsch.

when trees break. An avalanche dynamics model should distinguish between the two protective modes when predicting avalanche runout and velocity in forested terrain.

The tree-breaking threshold depends on both the avalanche loading and tree strength. Trees fall if (1) the bending stress exerted by the moving snow exceeds the bending strength of the tree stem (Johnson, 1987; Peltola and Kellomäki, 1993; Peltola et al., 1999; Mattheck and Breloer, 1994) or (2) if the applied torque overcomes the strength of the root-soil plate, leading to uprooting and overturning (Coutts, 1983; Jonsson et al., 2006). Avalanche loading is more difficult to quantify because it depends primarily on the avalanche flow regime. To define the avalanche loading, avalanche flow density, velocity and height must be known. These vary across the avalanche flow body and evolve along the avalanche track. The best example is the structure of a dry, mixed avalanche containing both a flowing core and powder cloud. The core velocity and density vary in the streamwise flow direction. For example, the avalanche front can have different flow characteristics than the avalanche tail. Destruction is defined by the dynamic avalanche loading. In the case of wet snow avalanches, the velocities are smaller and destruction is defined by quasi-static loadings.

The primary goal of this paper is to introduce tree breaking into avalanche dynamics calculations in order to toggle between different frictional processes acting on the avalanche. We therefore define four loading cases representing four different avalanche flow regimes. These are powder, intermittent, dry and wet. We assume tree breaking is always in bending, independent of the flow regime. Failure is defined by a bending stress threshold. The bending stress for mixed dry avalanches is defined by dynamic impact pressures. The wet flow regime requires an equation to describe the indeterminate, quasi-static loading of wet avalanches. We compare the loadings to tree strength to find the critical flow properties (density, velocity, height) for a particular flow regime to break trees. Real case studies are used for this purpose. We carried out a field campaign in summer 2014 in Monbiel and Täsch (Switzerland) and investigated forest damage by avalanches in detail. We compare these observations with avalanche dynamics simulations to reconstruct the spatial extent of the pressure field. Forest damage by dry avalanches that occurred in southern Germany in 2009 are additionally simulated to test the breaking/non-breaking bending stress thresholds.

\section{Avalanche loading}

\subsection{Avalanche pressure and tree stress}

Avalanches exert a pressure $p$ on a tree. We make the magnitude of this pressure a function of avalanche flow regime. We consider dry (superscript d) and wet (superscript w) avalanche flow regimes separately (Table 1).

A dry avalanche is divided into a dense flowing core (subscript $\Phi$ ) and a powder cloud (subscript П) (Fig. 2). The powder cloud consists of an ice dust suspension with bulk density $\rho_{\Pi}$. The height of the cloud $h_{\Pi}$ is generally larger than the height of the avalanche core $h_{\Phi}$. The avalanche core can flow in a highly disperse, saltation-like manner, especially at the avalanche front. This leads to an "intermittent" impact pressure. We therefore term this flow regime "intermittent", and the pressure is defined by impulsive granular impacts (subscript g). The intermittent layer and the avalanche core contain snow granules with density $\rho_{\mathrm{g}}$. When the spacing between the granules is small, the core pressure is uniformly distributed along the flow height and defined by the bulk flow density $\rho_{\Phi}^{\mathrm{d}}$ and the depth-averaged velocity $u$. The bulk flow density of the core is smaller than the granule density, $\rho_{\Phi}^{\mathrm{d}}<\rho_{\mathrm{g}}$. We therefore define three impact pressures associated with the dry avalanche flow regime: powder cloud $p_{\Pi}$, intermittent granular impacts $p_{\mathrm{g}}$ and bulk avalanche pressure of the core $p_{\Phi}^{\mathrm{d}}$ (Table 1).

A wet snow avalanche contains only a dense flowing core and exerts a pressure $p_{\Phi}^{\mathrm{W}}$ on the tree. We assume for the wet snow loading case, that the avalanche does not possess a powder cloud or that the flow core is sufficiently fluidized to apply an intermittent pressure on the tree. Typically, the density of the wet snow avalanche core $\rho_{\Phi}^{\mathrm{w}}$ is higher than the density of a similar dry avalanche (McClung and Schaerer, 1985; Bozhinskiy and Losev, 1998). The impact pressure $p_{\Phi}^{\mathrm{W}}$ arising from a wet snow avalanche is not impulsive as the flow velocity is small. The notation used to describe the four different flow regimes is summarized in Table 1. 
Table 1. Denotation for the different flow regimes: $\rho$ for density, $h$ for the flow height and $p$ for the impact pressure per $\mathrm{m}^{2}$. The load is distributed linearly along the tree besides the intermittent loading by the saltation-like flow which exerts the loading pointwise.

\begin{tabular}{llllll}
\hline Flow regime & Model type & Density & $\begin{array}{l}\text { Flow } \\
\text { height }\end{array}$ & Impact pressure & Loading \\
\hline \multirow{2}{*}{ dry, mixed } & $\begin{array}{l}\text { powder } \\
\text { intermittent }\end{array}$ & $\begin{array}{l}\rho_{\Pi} \\
\rho_{\mathrm{g}}\end{array}$ & $\begin{array}{l}h_{\Pi} \\
h_{\mathrm{g}}\end{array}$ & $\begin{array}{l}\text { dynamic, } p_{\Pi} \\
\text { granular impact, } p_{\mathrm{g}}\end{array}$ & $\begin{array}{l}\text { linear distributed } \\
\text { point }\end{array}$ \\
\hline \multirow{2}{*}{ dry, mixed, wet } & dense & $\rho_{\Phi}^{\mathrm{d}}$ & $h_{\Phi}$ & dynamic, $p_{\Phi}^{\mathrm{d}}$ & linear distributed \\
\hline \multirow{2}{*}{ wet } & creep and glide & $\rho_{\Phi}^{\mathrm{W}}$ & $h_{\Phi}$ & quasi-static, $p_{\Phi}^{\mathrm{W}}$ & linear distributed \\
& gliding block & $\rho_{\Phi}^{\mathrm{W}}$ & $h_{\Phi}$ & quasi-static, $p_{\Phi}^{\mathrm{W}}$ & linear distributed \\
\hline
\end{tabular}

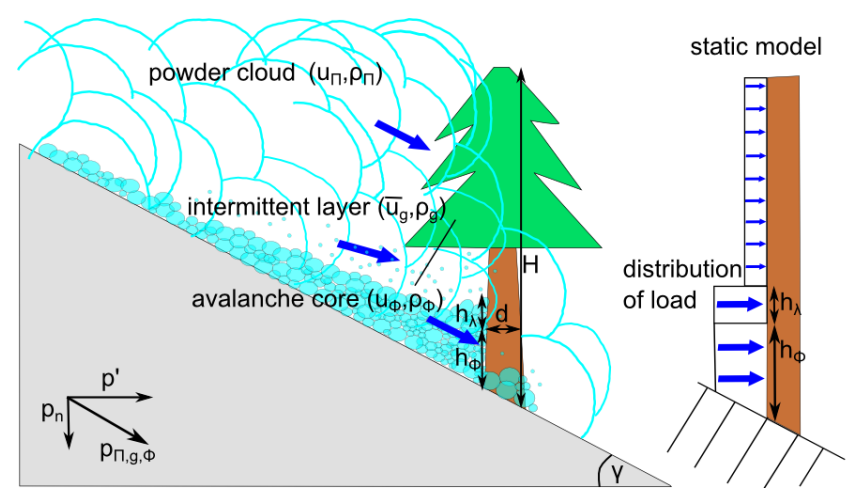

Figure 2. Schematic illustration of an avalanche with velocity $u$ on a slope with angle $\gamma$ hitting a tree. The avalanche has three parts: (1) the powder cloud $(\Pi),(2)$ the intermittent layer $(g)$ and (3) the wet- or dense-flow avalanche core $(\Phi)$. The density depends on the flow regime and is denoted $\rho_{\Pi}$ for powder clouds, $\overline{\rho_{\mathrm{g}}}$ for the intermittent flow consisting of granules with density $\rho_{\mathrm{g}}, \rho_{\Phi}^{\mathrm{d}}$ for dry snow avalanche cores and $\rho_{\Phi}^{\mathrm{W}}$ for wet snow avalanches. Flow height is denoted $h_{\Phi}$, stagnation depth $h_{\lambda}$ and the height of the tree $H$. The diameter of the stem is assumed to be constant $d(z)=d$. The impact pressure of the avalanche $p_{\Pi, \mathrm{g}, \Phi}$ is acting parallel to the slope and can be split in a vertical part due to gravitation $p_{\mathrm{n}}$ and a part perpendicular to the tree $p^{\prime}$. The static model and the assumed distribution of the load is depicted on the right hand side.

Because trees grow vertically, and the avalanche applies pressure in the slope parallel flow direction, the force $F$ is related to the avalanche impact pressure $p$ by

$F=p A \cos \gamma$,

where $A$ is the loading area of the tree, which depends on the affected height (impact height) and width of the tree. Moreover, $A$ depends on the avalanche flow regime. The angle $\gamma$ defines the slope inclination (see Fig. 2 and Table 2).

The total force $F$ with the moment arm defines the bending moment $M$

$M=F \frac{h_{\mathrm{a}}}{2}$,
Table 2. Denotation to calculate the loading.

\begin{tabular}{llc}
\hline Symbol & Parameter & Unity \\
\hline$\rho$ & avalanche density & $\mathrm{kg} \mathrm{m}^{-3}$ \\
$u$ & flow velocity & $\mathrm{m} \mathrm{s}^{-1}$ \\
$h_{\mathrm{a}}$ & impact height & $\mathrm{m}$ \\
$\lambda$ & stagnation constant & \\
$c_{\mathrm{d}}$ & drag coefficient & \\
$\sigma$ & bending stress & $\mathrm{Pa}$ \\
$\bar{\sigma}$ & bending strength of tree & $\mathrm{Pa}$ \\
$p$ & applied pressure & $\mathrm{Pa}$ \\
$F$ & applied force & $\mathrm{N}$ \\
$M$ & bending moment & $\mathrm{Nm}$ \\
$I$ & moment of inertia & $\mathrm{m}$ \\
$A$ & loading area & $\mathrm{m}$ \\
$\gamma$ & slope angle & $\circ$ \\
$d$ & stem diameter & $\mathrm{m}$ \\
$H$ & tree height & $\mathrm{m}$ \\
$w$ & effective crown width & $\mathrm{m}$ \\
$l_{\mathrm{V}}$ & volume length & $\mathrm{m}$ \\
$\psi$ & opening angle & $\circ$ \\
$\mu$ & friction angle & $\circ$ \\
$N$ & gliding factor & \\
$K$ & creep factor & \\
$\eta$ & efficiency factor & \\
$c^{*}$ & intensity factor & \\
$D$ & magnification factor & \\
$r$ & granule radius & $\mathrm{m}$ \\
\hline & &
\end{tabular}

where $h_{\mathrm{a}}$ is the impact height of the avalanche on the tree. The stress $\sigma$ is defined by

$\sigma=\frac{M d}{2 I}$

where $d$ is the diameter of the tree and $I$ is the moment of inertia of the stem cross-section (Table 2). As we assume round tree trunks,

$I=\frac{\pi d^{4}}{64}$ 
and therefore

$\sigma=32 \frac{M}{\pi d^{3}}$.

The bending stress is calculated from the maximum torque, which is located at the stem base. We assume a fixed support and a homogenous distribution of mass and velocity (see Fig. 2). We do not account for shearing. In this analysis we make use of Mattheck's observation that the tree grows with respect to the applied forces imposed by the natural environment, for example wind (Mattheck and Breloer, 1994). This implies that the tree strength $\bar{\sigma}$ in relation to the applied moment is independent of height and therefore constant for a single tree and must only be determined at one point. We select this point to be the tree stem base. Mattheck's observation also implies that the moments to break the tree in bending and to overturn the tree are similar (Bartelt and Stöckli, 2001; Peltola et al., 1999).

\subsection{Four avalanche flow regimes $p_{\Pi}, p_{\mathrm{g}}, p_{\Phi}^{\mathrm{d}}, p_{\Phi}^{\mathrm{w}}$}

Various studies have investigated avalanche impact pressures on obstacles (Pedersen et al., 1979; Lang and Brown, 1980; Faug et al., 2004, 2010; Gray et al., 2003; Hauksson et al., 2007; Naaim et al., 2004, 2008; Sheikh et al., 2008; Teufelsbauer et al., 2011; Baroudi et al., 2011). Pressures $p$ from fast moving avalanches in the dry flow regime are represented by the equation

$p=c_{\mathrm{d}} \rho \frac{u^{2}}{2}$.

This formula is recommended by the Swiss guidelines on avalanche dynamics calculations (Salm et al., 1990) as well as the report from the European commission on the design of avalanche protection dams (Johannesson et al., 2009). It describes the local momentum exchange between the avalanche and a rigid slender obstacle at impact. The drag coefficient $c_{\mathrm{d}}$ accounts for the obstacle geometry and flow regime (Salm et al., 1990; Johannesson et al., 2009).

The pressure formula Eq. (6) has been applied to backcalculate measurements of pressure exerted by wet snow avalanches on obstacles (Sovilla et al., 2010). Application of this formula to the wet snow avalanche problem assumes that the pressures arise from a quasi-static flow regime. However, to model the measured pressures with the observed avalanche velocities requires using unrealistic and non-physical drag coefficients, $c_{\mathrm{d}}>2$. This suggests that the nature of the wet snow avalanche pressure is not dynamic, but similar to quasistatic glide pressures exerted on pylons and defense structures. For the wet snow case $p_{\Phi}^{\mathrm{w}}$, we assume that dynamic pressures are small in comparison to the static pressure arising from the weight of the snow that loads the tree. Our assumption is based on observations of wet snow avalanche deposits and levee formation (Bartelt et al., 2012b; Feistl et al., 2014b). Often wedges of snow pile up upstream of trees. The avalanche flows around these stationary pile-ups; shear planes develop. Any dynamic force must be transferred by frictional mechanisms across the shear planes separating the stationary and moving snow. We assume these dynamic forces to be small, and that the total force acting on the tree depends on the distribution of quasi-static forces behind the obstacle. This is an indeterminate problem because it depends on the terrain and roughness in the vicinity of the obstacles. Therefore, we assume that the applied pressure cannot be represented by Eq. (6) which describes only the local transfer of momentum and not the static weight of the avalanche pushing on the obstacle. We present the application of two possible alternative calculation methods. The first (we term it "creep pressure model", CPM) is based on the Swiss guidelines on avalanche protection measures (Margreth, 2007) and the report of the European commission (Johannesson et al., 2009). The second method (we term it "sliding block model", SBM) was used to investigate the formation of glide snow avalanches, based on the failure of the stauchwall (Bartelt et al., 2012a; Feistl et al., 2014a). In this model the stauchwall is replaced by the tree. The model is similar to the approach developed by In der Gand and $\mathrm{Zu}$ pančič (1966) to find glide-snow pressure acting on obstacles.

\subsubsection{Powder cloud loading $p_{\Pi}$}

The pressure exerted by the powder cloud is

$p_{\Pi}=c_{\Pi} \rho_{\Pi} \frac{u_{\Pi}^{2}}{2}$,

where $c_{\Pi}$ is the powder cloud drag coefficient of loading on the entire tree depending on tree species and wind speed (Mayhead, 1973). Mayhead (1973) derived an average value of $c_{\Pi}=0.4$ for different tree species in Great Britain in wind tunnel experiments for wind speeds of $u=25 \mathrm{~m} \mathrm{~s}^{-1}$. We adopt this value for the powder cloud loading. Mayhead (1973) found decreasing drag coefficient values for increasing velocities. The total force is

$F_{\Pi}=p_{\Pi} w H \cos \gamma$

for a homogeneous distributed loading.

The total force $F_{\Pi}$ depends on the powder cloud height $h_{\Pi}$ and on the tree height $H$. We assume the powder cloud to be larger than the tree height $h_{\Pi}>H$, therefore $H$ is the impact height. The quantity $w$ is the loading width of the tree (Table 2). In this analysis we assume the width to be constant over height $w(z)=w$ as indicated in Fig. 3. The loading width depends on the location of the tree in the forest (Indermühle, 1978). Single trees in the avalanche path have a larger loading width than trees in dense forest stands. Leafless trees have smaller loading widths than evergreen trees (Fig. 3). Larch and birch trees for example have smaller loading widths than spruce or pine trees. The loading width can 

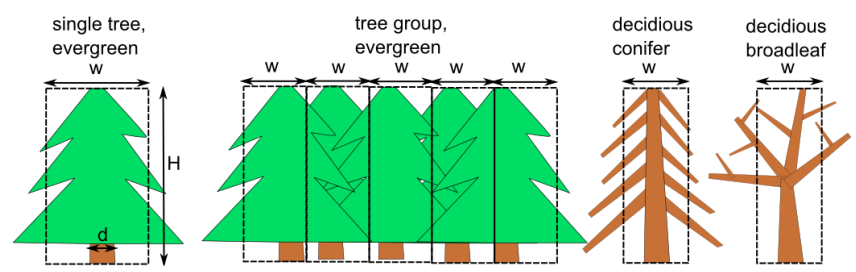

Figure 3. The loading width of the tree depends on the location in the forest. In dense forest stands tree crowns tend to be narrower than if they stand alone. Additionally the loading width $w$ depends on the foliation of different tree species.

be estimated from aerial photographs. The relationship between stem diameter and crown diameter was evaluated by Indermühle (1978), Bürki (1981) and Pretzsch (2014).

The bending stress of a powder cloud is then

$\sigma_{\Pi}=c_{\Pi} \rho_{\Pi} \frac{8 u_{\Pi}^{2}}{\pi d^{3}} w H^{2} \cos \gamma$

\subsubsection{Intermittent loading $p_{\mathrm{g}}$}

The pressure exerted by an individual snow granule is

$p_{\mathrm{g}}=\rho_{\mathrm{g}} \frac{4 u_{\mathrm{g}}^{2}}{3}$

(Bozhinskiy and Losev, 1998). This equation assumes the complete destruction of the snow granule within the impact time interval $r / u_{\mathrm{g}}$ where $r$ is the granule radius. For a granule with $r=0.1 \mathrm{~m}$ and a velocity $u_{\mathrm{g}}=20 \mathrm{~m} \mathrm{~s}^{-1}$ the time of impact is $0.005 \mathrm{~s}$. The force of the granule impact is applied over an area $\pi r^{2}$. The total impact pressure on the tree is the sum of the point loads exerted by the granules $\sum p_{\mathrm{g}}$. The granule densities can be large $\left(\rho_{\mathrm{g}}>300 \mathrm{~kg} \mathrm{~m}^{-3}\right)$. The number of granules that hit the tree per unit time depends on the speed of the avalanche and the height and average density $\overline{\rho_{\mathrm{g}}}$ of the intermittent layer. The momentum exerted by a number $n$ of granules that hit the stem is therefore

$M_{\mathrm{g}}=p_{\mathrm{g}} \pi r^{2} \cos \gamma \sum_{\mathrm{i}=1}^{n} h_{\mathrm{i}}$,

where $h_{\mathrm{i}}$ is the impact height of a single granule. The total momentum of the intermittent loading case is governed by the distribution of the impact pressure exerted by the granules in height. We assume the height of the intermittent layer $h_{\mathrm{g}}$ to be as large as the flow height of the core $h_{\Phi}$ plus the stagnation depth $h_{\lambda}, h_{\mathrm{g}}=h_{\mathrm{a}}$ (see Eq. 17). Certainly there are single granules hitting the tree higher up on the stem, but the number and mass of these granules is small. Additionally we assume a regular distribution of impacts; therefore

$\sum_{\mathrm{i}=1}^{n} h_{\mathrm{i}} \approx n h_{\mathrm{a}} / 2$
This assumption is conservative considering an avalanche flow with highest intensity in the lower most part. That is in contrast to loading by wind (see Fig. 4).

The average density $\overline{\rho_{\mathrm{g}}}$ times the volume with length $r$, height $h_{\mathrm{a}}$ and width $d$ is equal to the mass of $n$ granules with radius $r$ in the identical volume; therefore

$\overline{\rho_{\mathrm{g}}} h_{\mathrm{a}} d r=\rho_{\mathrm{g}} \frac{4}{3} \pi r^{3} n$

(see Fig. 4).

We solve this equation for $n$ and take the assumption of regular distribution (Eq. 12) into account. Then Eq. (11) results in

$M_{\mathrm{g}}=\overline{\rho_{\mathrm{g}}} \frac{u_{\Phi}^{2}}{2} d h_{\mathrm{a}}^{2} \cos \gamma$,

which is similar to the momentum exerted by the dense flowing core $M_{\Phi}$ for a drag coefficient $c_{\Phi}=2$ and $\overline{\rho_{\mathrm{g}}}=\rho_{\Phi}$. The average density of the intermittent layer will, however, always be considerably lower than the density of the flowing core. We therefore assume $M_{\Phi}>M_{\mathrm{g}}$ and do not consider the intermittent loading for the bending stress analysis, although we recognize that the forces from individual particles can be large.

\subsubsection{Dense flowing core loading $p_{\Phi}^{\mathrm{d}}$}

The pressure per unit area that a dense flowing avalanche exerts on a tree is calculated similarly to the powder cloud loading except that now we consider the avalanche core $\Phi$ :

$p_{\Phi}^{\mathrm{d}}=c_{\Phi} \rho_{\Phi}^{\mathrm{d}} \frac{u_{\Phi}^{2}}{2}$.

Fluidization leads to bulk avalanche flow densities $\rho_{\Phi}$ that vary in the streamwise flow direction. Values for $c_{\Phi}$ for cylindrical obstacles (trees) are in a range between $1<c_{\Phi}<2$ depending on the literature (McClung and Schaerer, 1985; Norem, 1991). For our analysis we chose $c_{\Phi}=1.5$ according to Johannesson et al. (2009) for trees in dry flowing avalanches. The loading width is equal to the stem diameter $w=d$ if the fluidized height $h_{\Phi}$ of the avalanche is located beneath the tree crown; therefore

$\sigma_{\Phi}^{\mathrm{d}}=c_{\Phi} \rho_{\Phi}^{\mathrm{d}} \frac{8 u_{\Phi}^{2}}{\pi d^{2}} h_{\mathrm{a}}^{2} \cos \gamma$

The loading is adjusted to account for the stagnation height $h_{\lambda}$

$h_{\mathrm{a}}=h_{\Phi}+h_{\lambda}$,

and we denote $h_{\mathrm{a}}$ as impact height. The stagnation height is calculated according to the Swiss guideline formula

$h_{\lambda}=\frac{u_{\Phi}^{2}}{2 g \lambda} b\left(d, h_{\Phi}\right)$,

where $b\left(d, h_{\Phi}\right)=0.1$ for a flow height $h_{\Phi} \gg d$ (Salm et al., 1990). Furthermore, $\lambda=1.5$ for fluidized flows. 


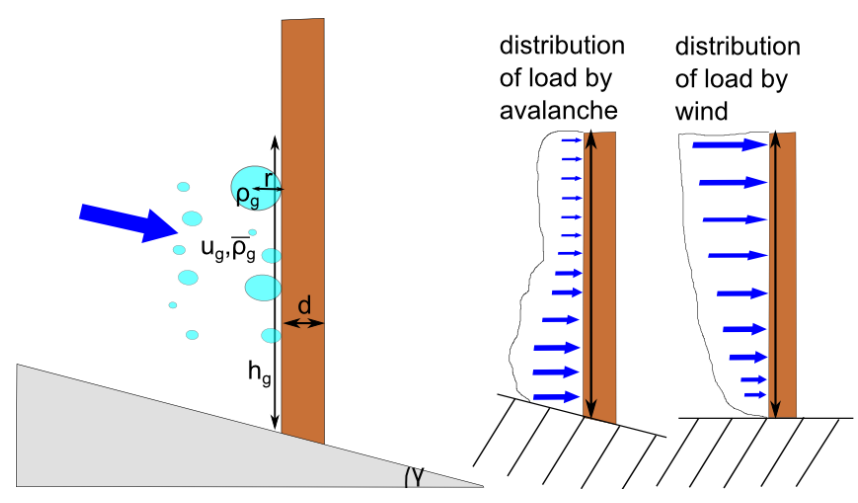

Figure 4. Granules of the intermittent layer with density $\rho_{\mathrm{g}}$ hitting a tree with diameter $d$. The average density $\overline{\rho_{\mathrm{g}}}$ is calculated over the whole flow height $h_{\mathrm{g}}$. The momentum $M_{\mathrm{g}}$ is applied by the granules on an area $\pi r^{2}$ on the stem for a time $t=r / u_{\mathrm{g}}$ (Bozhinskiy and Losev, 1998). The difference between loading by an avalanche in comparison to loading by wind is depicted on the right hand side.

\subsubsection{Creep pressure model $p_{\Phi}^{\mathrm{w}}(\mathrm{CPM})$}

We apply the CPM developed by Salm (1978) and Häfeli (1967), which is applied in the Swiss Guidelines on avalanche prevention (Margreth, 2007) to calculate the snow pressure of snow gliding:

$p_{\Phi}^{\mathrm{w}}=\rho_{\Phi}^{\mathrm{w}} g K N \eta \frac{h_{\Phi}}{2 \cos \gamma}$,

where

$$
\begin{aligned}
K= & \left(2.5\left(\frac{\rho_{\Phi}^{\mathrm{W}}}{1000}\right)^{3}-1.86\left(\frac{\rho_{\Phi}^{\mathrm{W}}}{1000}\right)^{2}\right. \\
& \left.+1.06\left(\frac{\rho_{\Phi}^{\mathrm{W}}}{1000}\right)+0.54\right) \sin (2 \gamma)
\end{aligned}
$$

is the creep factor, $N$ the gliding factor and

$$
\eta=1+c^{*} \frac{h_{\Phi} \cos \gamma}{d}
$$

the efficiency factor (Table 2). According to Eq. (5) the bending stress is calculated by

$$
\sigma_{\Phi}^{\mathrm{w}}=\rho_{\Phi}^{\mathrm{w}} g K N \eta \frac{8 h_{\Phi}}{\pi d^{2}} h_{\mathrm{a}}^{2} .
$$

\subsubsection{Sliding block model $p_{\Phi}^{\mathrm{w}}(\mathrm{SBM})$}

A second method to calculate glide snow pressure was developed by In der Gand and Zupančič (1966). In this method the snow exerts a quasi-static pressure on the tree (Fig. 5). The magnitude of the quasi-static pressure depends on the volume of snow captured. The pressure will be highest before a wedge with shear planes develops behind the tree. The angle $\psi$ and the length $l_{\mathrm{v}}$ are used to define the volume, see Fig. 5. The opening angle $\psi$ depends on the location of the

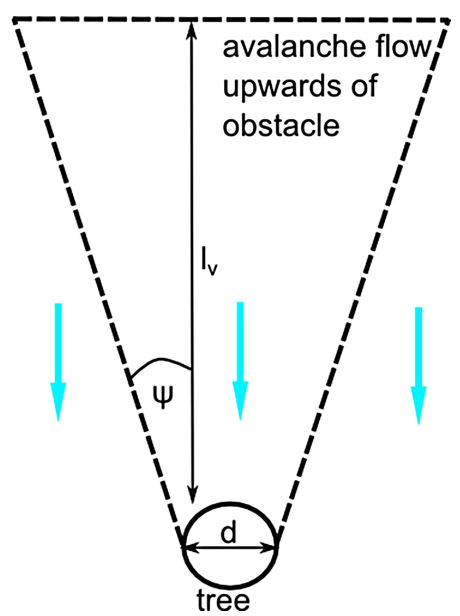

Figure 5. Schematic illustration of a wet snow accumulation behind a tree. The volume of the snow depends on the opening angle $\psi$, the volume length $l_{\mathrm{V}}$ and the width of the tree $d$.

tree in the forest and the forest structure, because pressure can be distributed to other tree groups in the forest. The snow is pushing on the tree along force chains that were observed in granular experiments (e.g., Geng and Behringer, 2005) and develop randomly with differing opening angles and changing volume lengths. The volume length $l_{\mathrm{v}}$ depends on the terrain and the avalanche length. It increases for open slopes and long avalanches and decreases for rough, twisted avalanche tracks where surface elements and channel sides take up the avalanche pressure. Surface roughness is parameterized with the ground friction coefficient $\mu_{\mathrm{m}}$ (Table 2).

The quasi-static pressure of the avalanche in this case is therefore

$p_{\Phi}^{\mathrm{W}}=\rho_{\Phi}^{\mathrm{W}} g h_{\Phi} l_{\mathrm{v}}\left(l_{\mathrm{V}} \tan \psi+d\right)\left(\sin \gamma-\mu_{\mathrm{m}} \cos \gamma\right) \cos \gamma$.

The bending stress of the avalanche on the tree is then

$$
\begin{aligned}
\sigma_{\Phi}^{\mathrm{W}}= & \rho_{\Phi}^{\mathrm{W}} g l_{\mathrm{V}}\left(l_{\mathrm{v}} \tan \psi+d\right)\left(\sin \gamma-\mu_{\mathrm{m}} \cos \gamma\right) \\
& \cdot \frac{16 h_{\Phi}}{\pi d^{2}} h_{\mathrm{a}}^{2}(\cos \gamma)^{2} .
\end{aligned}
$$

\subsection{Additional loading}

The bending stress equation for powder avalanches $\sigma_{\Pi}$ (Eq. 9), dry avalanches $\sigma_{\Phi}^{\text {d }}$ (Eq. 16) and wet snow avalanches $\sigma_{\Phi}^{\mathrm{W}}$ (Eqs. 22 and 24) can be increased to include several effects that are not included in the ideal case. The stresses are magnified by the amount $D$. In the ideal case $D=1$. Reasons for a magnification factor $D>1$ are the following.

- The avalanche exerts the pressure not only on the stem but also on low branches. Trees at the stand edge usually have branches close to the ground surface as light 
conditions are favorable. This effect is especially pronounced for evergreen trees such as spruces. We therefore assume that the stem diameter is a poor measure for the effective width at stand edge. For trees with lowlying branches at the forest edge, we assume a magnification factor between 1.5 (leafless trees) and 2.5 (evergreen trees), $1.5<D<2.5$. As powder clouds exert their pressure on the whole tree anyway, this does not affect Eq. (9), $D=1$. The difference in loading area from evergreen to leafless trees is accounted for by the varying effective width $w$ (Fig. 3).

- Woody debris carried by the avalanche increases the impact pressure when hitting a tree. Similar to the additional point load exerted by single snow granules $p_{\mathrm{g}}$ (Sect. 2.2.2) the impact pressures can be high, especially for a wood density $\rho_{\mathrm{w}} \approx 800 \mathrm{~kg} \mathrm{~m}^{-3}$. There are countless impact scenarios of broken stems hitting trees below, leading to subsequent destruction. For the first trees at the stand edge this is not the case, however. We take this effect into account by assuming the flow density of the avalanche to contain woody debris if the avalanche has hit and entrained trees before; therefore $1.5<D<2$.

- The self weight of the tree when bending just before breaking is an additional load that increases the bending stress on the lower parts of the stem. This effect can even be higher if snow is loaded on branches and increases the tree mass. Second-order bending effects are thereby introduced into the problem (Peltola et al., 1997). We assume an increase in bending stress of approximately $10-20 \%$.

- For flexible structures such as trees, the inertial response of the tree must be considered (Clough and Penzien, 1975). The magnification factor $D$ depends on the mass and stiffness of the obstacle as well as the duration of the impulsive loading. Clough and Penzien (1975) calculated a value $D \approx 1.7$. This effect is relevant only for powder snow loading.

- We assumed in all four flow regimes that the avalanche flows close to the ground. However, an avalanche flowing over a deep snow cover will hit the tree higher up the stem. This effect can be included in the analysis by simply increasing the moment arm of applied force. Whereas the increase in momentum can be high at stand edges where deep snow covers occur, the effect is negligible where dense canopy suppresses snow accumulation on the ground. The increase of the exerted pressure is $50 \%$ if an avalanche with flow height $h_{\Phi}=3 \mathrm{~m}$ hits a tree above an $80 \mathrm{~cm}$ deep snow cover.
Table 3. Bending strength of different tree species according to Peltola et al. (2000) who performed tree pulling experiments. Note that these values are average values and vary depending on the healthiness, the location in the forest and other stand characteristics.

\begin{tabular}{lcccc}
\hline & Spruce & Scots Pine & Larch & Birch \\
\hline $\begin{array}{l}\text { Bending strength } \bar{\sigma} \\
\left(\mathrm{MN} \mathrm{m}^{-2}\right)\end{array}$ & 36 & 37 & 37 & 41 \\
\hline
\end{tabular}

\subsection{Tree breaking}

Trees break if the bending stress exerted by the avalanche exceeds the bending strength of the tree $\sigma>\bar{\sigma}$. In forest areas the bending strength is highly variable, depending on the tree species, their location in the forest, on the soil characteristics and its nutrient content, on the trees' healthiness, on the temperature and on the moisture content of the wood (Grosser and Teetz, 1985; Götz, 2000; Peltola et al., 2000; Lundström et al., 2009). Bending strengths of wood provided in literature do not only vary according to stand and tree characteristics but also depend on the measuring method, for example if the load is applied dynamically or quasi-statically. Tree pulling experiments (Peltola et al., 2000; Stokes et al., 2005), rock impact experiments (Lundström et al., 2009), fractometer measurements by Götz (2000) and material testing procedures by Lavers (1983) result in different values for the bending strength: from $\bar{\sigma}=6 \mathrm{MN} \mathrm{m}^{-2}$ for spruce (Götz, 2000) to $\bar{\sigma}=150 \mathrm{MN} \mathrm{m}^{-2}$ for birch (Grosser and Teetz, 1985). The values we used to predict forest damage in our model calculations are based on the study of Peltola et al. (2000) and are listed in Table 3. The bending stress of avalanches to destroy mature trees must exceed a minimum value of $\sigma>30 \mathrm{MN} \mathrm{m}^{-2}$. According to Peltola et al. (2000); Götz (2000) and Stokes et al. (2005) spruce is the species with lowest strength, whereas birch is the strongest of the investigated samples.

We only calculate the stress that is sufficient to break trees not to uproot trees. Previous studies proved that pressures required for uprooting are in the same range or higher than for stem breakage (Bartelt and Stöckli, 2001; Peltola et al., 1999). Additionally we observed twice as many tree breakages than uprootings in the two documented events Täsch and Monbiel (broken: 324, uprooted: 173).

\section{Modeling and results}

\subsection{Forest destruction modeling}

To test the performance of Eq. (16) on forest damage by dry flowing avalanche cores, we implemented a new module in the avalanche simulation program RAMMS (Christen et al., 2010b). We accounted for the turbulent movement of particles, curvature effects, snow temperature and cohesion 
(Buser and Bartelt, 2009; Fischer et al., 2012; Vera et al., 2015; Bartelt et al., 2014, 2015). Avalanche flow regime depends on snow temperature and moisture content (Vera et al., 2015). Temperature controls the mechanical behavior of the snow particles that comprise the avalanche core. Wet snow avalanches form from warm, moist snow and typically flow in a dense, frictional flow regime. Dry mixed/powder avalanches form from cold, dry snow. Dry snow avalanches exhibit a more disperse behavior and are often accompanied by a powder cloud. Each flow regime is associated with a characteristic impact pressure. We denote this RAMMS version as "extended".

Bending stresses exerted on trees of specific forest areas are calculated for each grid cell from flow height, density, velocity and slope angle. Additionally for each forest area an average stem diameter has to be specified. The bending strength of the predominant tree species is taken from literature (Table 3). The trees in an area are destroyed if $\sigma>\bar{\sigma}$. We denote both, broken and uprooted trees as "destroyed". In this case, the avalanche is slowed down by the increased turbulent friction and the entrainment of the woody debris in this area (Bartelt and Stöckli, 2001). Detrainment of snow is dominant in areas where $\sigma<\bar{\sigma}$ and no destruction takes place (Feistl et al., 2014b).

We applied the new model approach to back calculate avalanche events with forest damage in Switzerland and Germany. Calculated forest damage was compared to the actual observed damage. Stem diameters in $1.3 \mathrm{~m}$ height, tree species and exact tree location were documented for two avalanche events with forest destruction in Monbiel and Täsch, Switzerland. In total we documented 324 broken, 173 uprooted trees and 710 trees that withstood the avalanche loading. Six avalanches with forest destruction, that released in an avalanche cycle in winter 2009 in Germany were additionally simulated to test on the model performance.

\subsection{Wet snow avalanche Monbiel, 2008}

A large wet snow avalanche (release volume approx. $150000 \mathrm{~m}^{3}$ ) released spontaneously on 23 April 2008 near Monbiel, Switzerland and destroyed a small spruce forest before it stopped in the river bed of the Landquart. An approximation of the flow velocity $\left(u=5 \mathrm{~m} \mathrm{~s}^{-1}\right)$ and flow height $\left(h_{\Phi}=3 \mathrm{~m}\right)$ was possible by analyzing a movie documentation (Sovilla et al., 2012). The deposition height was measured using laser scan (between 2 and $7 \mathrm{~m}$ ). Subsequently this avalanche was simulated by Vera et al. (2015) with the avalanche modeling software RAMMS, applying a new model extension that accounts for random kinetic energy fluxes, cohesion and snow temperature (Buser and Bartelt, 2009; Bartelt et al., 2015). They compared the model results with the data and Vera et al. (2015) found the calculated velocities, flow heights and deposition heights to resemble the real avalanche flow (Fig. 6). These calculations allowed us to determine the impact pressure $p_{\Phi}^{\mathrm{w}}$ in the area of forest destruction. The slope angle at the location of the spruces was $10^{\circ}<\gamma<20^{\circ}$. The density of the avalanche deposition was estimated by Sovilla et al. (2012) to be $500 \mathrm{~kg} \mathrm{~m}^{-3}$ and Vera et al. (2015) estimated that the density of the flowing avalanche was slightly lower, approx. $450 \mathrm{~kg} \mathrm{~m}^{-3}$. This latter value was used for our simulations. The average stem diameter of the lower spruce stand, where all trees were broken, was approximately $d=0.5 \mathrm{~m}$ (Fig. 6). We calculated the impact pressures $p_{\Phi}^{\mathrm{W}}$ and the resulting bending stresses $1 \mathrm{MNm}^{-2}<\sigma<8 \mathrm{MN} \mathrm{m}^{-2}$ with the dynamic approach (Eq. 16) for all damaged trees. These values are far below the bending strength $\bar{\sigma}=36 \mathrm{MN} \mathrm{m}^{-2}$ of spruces. We additionally calculated the bending stress with the CPM and SBM and show the result for one spruce (Fig. 6, red cross) in Table 4.

\subsection{Powder snow avalanche Täsch, 2014}

A cold powder snow avalanche released on 4 March 2014 in Täsch in Wallis, Switzerland. The road and the rail tracks to Zermatt were buried in deep snow. Aerial pictures and the insight of our visit to the site the next day allowed us to reconstruct the avalanche release volume (approx. $80000 \mathrm{~m}^{3}$ ), deposition patterns and forest damage along the track (Fig. 7). We used a dGNSS (differential Global Navigation Satellite System) device to measure the deposition heights. In summer 2014 we carried out a field campaign to document the forest destruction in detail. Approximately 1000 uprooted (165), broken (259), bent and still healthy trees (696) were mapped, their stem diameter measured and their species noted. The location of the trees and their characteristics are depicted in Fig. 7. Due to terrain undulations, the avalanche split in two parts in the lower part of the slope leaving trees in the central area untouched. Two old larch trees (at least 200 years old, measured with a pole testing drill) with stem diameters of 88 and $95 \mathrm{~cm}$ resisted the impact pressure in the main avalanche path (pink crosses in Fig. 7).

Approximately $10 \mathrm{~m}$ high deflecting dams were built along the north side of the avalanche path to protect the village Täsch from being hit by extreme avalanche events. These dams worked well in the upper part of the avalanche path where the avalanche hardly overflew the dam. In the lower part, however, the dam lost its deflecting effect because of avalanche depositions of earlier events. The channel was almost filled up to the dam crown, and the avalanche from 4 March partly went straight down the slope. A young forest, consisting mainly of birches and larches was destroyed, and the avalanche hit the road north of the gallery, went through the river bed and hit the rail tracks on the other side (see Fig. 7).

Velocities, flow height and the powder cloud diffusion were modeled with the extended RAMMS version. We assume snow entrainment along the track, with $0.5 \mathrm{~m}$ entrained snow in an elevation of $2500 \mathrm{~m}$ decreasing by $10 \mathrm{~cm}$ every 100 -height meters. The velocity driven entrainment law 


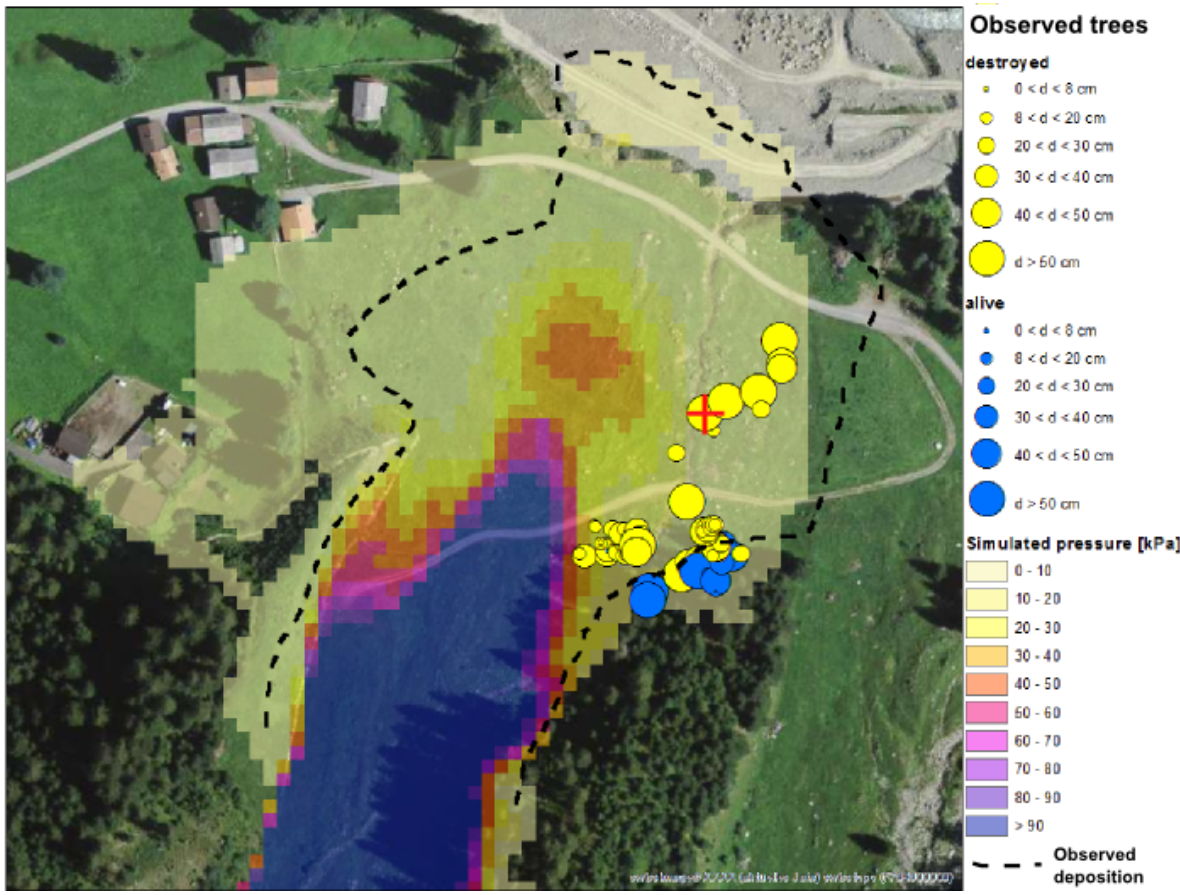

Figure 6. Simulated dynamic impact pressure $p_{\Phi}$ of the wet snow avalanche in Monbiel, calculated with RAMMS taking snow temperature and cohesion (Vera et al., 2015; Bartelt et al., 2015) into account. The tree species and stem diameters were measured during a field campaign in summer 2014. The tree location was measured with a dGNSS device. The red cross denotes one spruce that we calculated the bending stress $\sigma$ for (Sect. 4) (Swissimage ${ }^{\circledR}$, DV 033594, 2014). Note that the calculated velocity and runout distance agreed well with the observations.

Table 4. Bending stress $\sigma$ and impact pressure $p$ that was exerted on three larches in Täsch and one spruce in Monbiel (Figs. 6, 7) for constant slope angle $\gamma=25^{\circ}$ in Täsch and $\gamma=10^{\circ}$ for the avalanche in Monbiel. The drag coefficient was $c_{\Phi}=1.5$ for the avalanche core and $c_{\Pi}=0.4$ for the powder snow avalanche. For the CPM we assume $c^{*}=2, N=3.0$. To calculate the stagnation height $h_{\lambda}$ we chose $\lambda=1.5$ and $b\left(h_{\Phi}, d\right)=0.1$ according to the Swiss guidelines (Margreth, 2007). To calculate the pressure with the SBM we assume a volume length $l_{\mathrm{V}}=20 \mathrm{~m}, \psi=15^{\circ}$ and the friction on the ground or on the gliding surface $\mu=0.1$. The trees in Täsch were approximately $H=28 \mathrm{~m}$ (west), $H=30 \mathrm{~m}$ (middle) and $H=32 \mathrm{~m}$ (east) high and had a width $w=3 \mathrm{~m}$ (west), $w=3 \mathrm{~m}$ (middle) and $w=3 \mathrm{~m}$ (east) (Indermühle, 1978). The stem diameters of the larches in Täsch were $d=0.66 \mathrm{~m}$ (west), $d=0.88 \mathrm{~m}$ (middle) and $d=0.95 \mathrm{~m}$ (east), and the stem diameter of the spruce in Monbiel was $d=0.75 \mathrm{~m}$.

\begin{tabular}{llcccccc}
\hline Avalanche type & Location & $\begin{array}{c}\rho \\
\left(\mathrm{kg} \mathrm{m}^{-3}\right)\end{array}$ & $\begin{array}{c}H, h_{\Phi} \\
(\mathrm{m})\end{array}$ & $\begin{array}{c}u \\
\left(\mathrm{~m} \mathrm{~s}^{-1}\right)\end{array}$ & $\begin{array}{c}d \\
(\mathrm{~m})\end{array}$ & $\begin{array}{c}\sigma \\
\left(\mathrm{MN} \mathrm{m}^{-2}\right)\end{array}$ & $\begin{array}{c}p \\
\left(\mathrm{kNm}^{-2}\right)\end{array}$ \\
\hline \multirow{3}{*}{ powder } & Täsch west & 5 & 28 & 20 & 0.66 & 45 & $<1$ \\
& Täsch middle & 5 & 30 & 25 & 0.88 & 34 & $<1$ \\
& Täsch east & 5 & 32 & 25 & 0.95 & 31 & $<1$ \\
\cline { 2 - 7 } dry core & Täsch west & 300 & 2 & 17 & 0.66 & 18 & 65 \\
& Täsch middle & 300 & 2 & 17 & 0.88 & 10 & 65 \\
\hline \multirow{2}{*}{ wet (dynamic) } & Täsch east & 300 & 2 & 17 & 0.95 & 9 & 65 \\
wet (CPM) & Monbiel & 450 & 3 & 5 & 0.75 & 3 & 8 \\
wet (SBM) & & 450 & 3 & 5 & 0.75 & 18 & 53 \\
\hline
\end{tabular}

was applied with $\kappa=7$ (frontal ploughing, Christen et al., 2010b) and a density of $200 \mathrm{~kg} \mathrm{~m}^{-3}$ was assumed for the entrained snow. The simulations enabled us to calculate bending stresses caused by the powder part $\sigma_{\Pi}$ and the dry flowing avalanche core $\sigma_{\Phi}^{\mathrm{d}}$. For the powder cloud we calculated a density $\rho_{\Pi}=5 \mathrm{~kg} \mathrm{~m}^{-3}$, velocity $u_{\Pi}=25 \mathrm{~m} \mathrm{~s}^{-1}$ and a flow height $h_{\Pi} \approx 40 \mathrm{~m}$, which was higher than the trees it passed and destroyed. The avalanche core was flowing with an approximate speed, $u_{\Phi}^{\mathrm{d}}=17 \mathrm{~m} \mathrm{~s}^{-1}$, flow height $h_{\Phi}=2 \mathrm{~m}$ and we assumed a density of $\rho_{\Phi}^{\mathrm{d}}=300 \mathrm{~kg} \mathrm{~m}^{-3}$. 


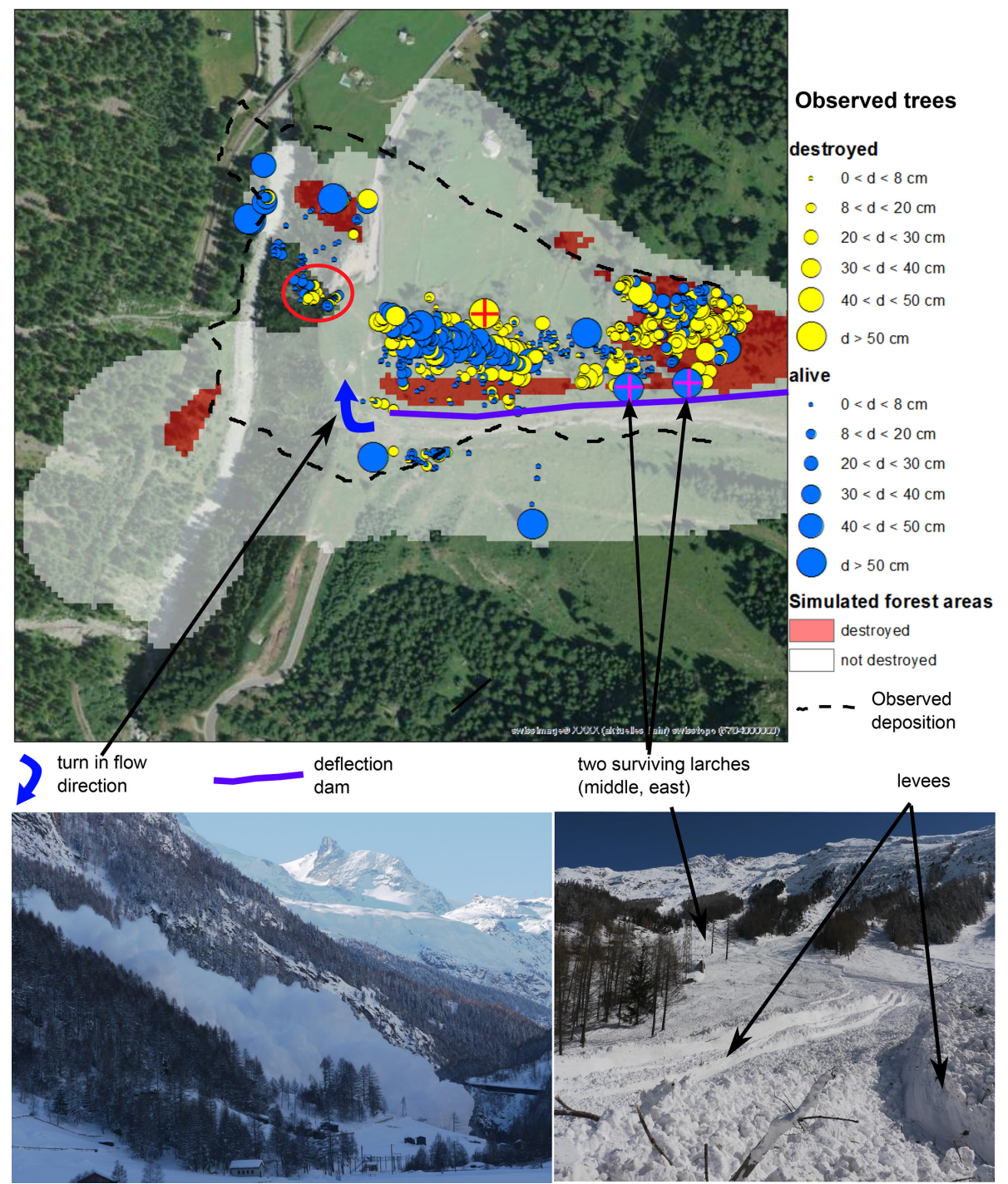

Figure 7. The calculated forest destruction with the new RAMMS module (red areas) in comparison to the observed forest stand (blue and yellow dots) and deposition area in Täsch. The simulated extent of the avalanche is underlaid with white. We chose the following parameter values to calculate this avalanche: $\xi=1500, \mu=0.55, \alpha=6 \%, \beta=0.9, R_{0}=2$ and entrainment along the track. The broken larch is marked with a red cross (west), whereas the two old larches in the upper part of the slope are marked with pink crosses (middle, east). A photo of the levees that lead to the direction change is added as well as the forest damage that followed (red circle). The avalanche ran over depositions of earlier events and overflew the dam (violet line) (Swissimage ${ }^{\circledR}$, DV 033594, 2014).

We calculated the forest destruction and compared the results with the actual observed tree damage (Fig. 7). Our simulation results correspond well with the observed destruction. The two old larches remain standing, whereas the young trees below the dam were broken (see Fig. 1). The forest in the lower central deposition area remained standing as observed. The avalanche turned right in the lower slope, shortly before the gallery and caused tree destruction in a forest stand shortly above the river bed (red circle in Fig. 7) before it went up the counter slope and hit the rail tracks. This turn in flow direction was caused by levee formation which could not be simulated with the avalanche modeling software. The levee formation is also the reason, why the avalanche did not reach as far as highlighted in the lower left corner of Fig. 7. The red cross denotes a broken larch we calculated the pressure for (see Sect. 4). The overflowing of the lower dam could be calculated assuming snow depositions of earlier events of approx. $5 \mathrm{~m}$ height.

\subsection{Powder snow avalanches Germany, 2009}

We simulated six avalanches that released in Germany end of February 2009 and tested the new model approach (Fig. 8). These avalanches were mapped by the Bavarian Avalanche Service from aerial images out of a helicopter. The for- 


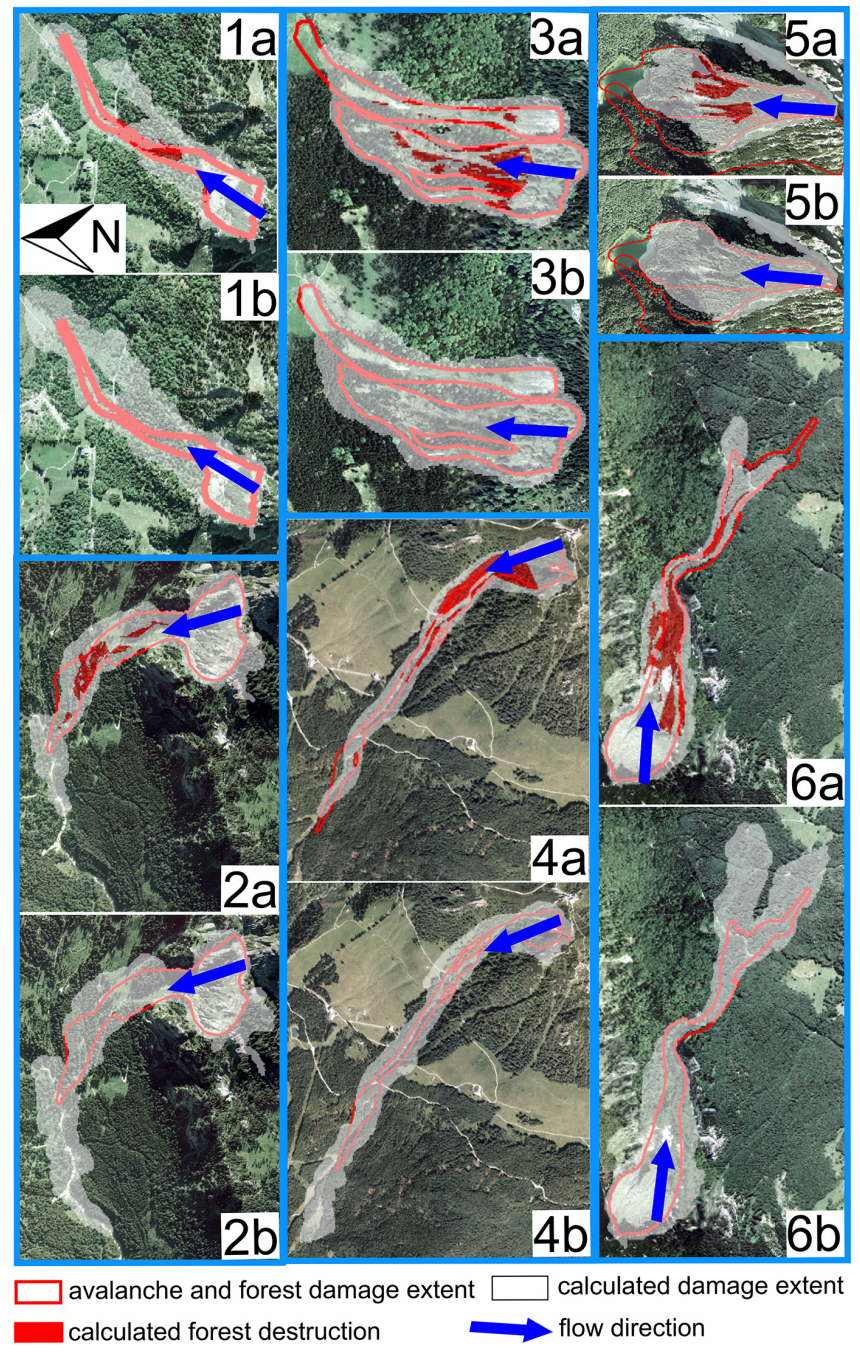

Figure 8. Simulation results for the dense flowing core for six avalanches with forest damage in Germany. The avalanches released at Wendelstein (1), Ahornalpe (2), Hochries (3), Spinnergraben (4), Frillensee (5) and Zwillingswand (6). In (a), forest was taken into account whereas (b) was modeled without forest. If bending stresses of the dry flowing core exceed the bending strength of trees (red areas) the turbulent friction increases, and the avalanche is slowed down. Detrainment occurs if the avalanche enters a forest area without damaging the trees. Note that the runout is shortened significantly if forest is taken into account. Forest destruction is well modeled in the upper parts of the avalanche paths and is underestimated in the lower parts. Large powder clouds developed in the lower avalanche paths and probably caused extensive destruction (Geobasisdaten $^{(\odot)}$ Bayerische Vermessungsverwaltung, Bayerisches Landesamt für Umwelt).

est damage and the avalanche extent were clearly visible. We chose $\mu$ and $\xi$ values according to an automatic procedure in RAMMS which takes terrain features, such as channels, gullies and flat areas into account (Christen et al., $2010 b)$. We did not consider the random movement of particles $(\alpha=0)$ for these avalanches. We accounted for cohe- sion $(c=50 \mathrm{~Pa})$ according to Dreier et al. (2014); Bartelt et al. (2015). The meteorological, release and entrainment conditions for these six avalanches were similar: cold temperatures $\left(-5^{\circ} \mathrm{C}\right)$, a release height of approximately $80 \mathrm{~cm}$ and snow entrainment along the avalanche path. A density of $200 \mathrm{~kg} \mathrm{~m}^{-3}$ for the entrained snow, $0.5 \mathrm{~m}$ of entrained snow in $1500 \mathrm{~m}$ elevation and frontal ploughing was assumed for these avalanches. They all released shortly above or below the treeline and caused massive forest destruction. Information from the Bavarian avalanche cadastre and forest inventories was used to define the return period of these events, which was at least 100 years. The damaged forest was mainly spruce with some areas of larch at higher elevations. The stem diameters $d$ and tree species were defined according to orthoimages (Bebi et al., 2001). Runout areas were overestimated if not taking forest into account (see pictures (a) in Fig. 8) with Frillensee as an exception. On average, the runout was overestimated by approx. $200 \mathrm{~m}$. When taking forest into account the runout was on average well reproduced (in average $30 \mathrm{~m}$ too short). Generally forest damage by the dense flowing core was underestimated especially in the lower part of the avalanche paths. Large powder clouds were observed, however, especially in the lower avalanche paths.

\section{Discussion}

Using the standard dynamic calculation formula for $\sigma_{\Phi}^{\mathrm{d}}$ (Eq. 6), we were able to reproduce the observed forest damage in the central and upper parts of the avalanche tracks in Täsch and Germany (see Sects. 3.3, 3.4). In these regions the calculated avalanches reached high velocities and therefore exerted large dynamic pressures on the trees. However, it was not possible to reproduce the observed forest damage in the runout zone or lateral edges of the flow without taking into account the avalanche flow regime, specifically using the formulas for powder snow pressure $\sigma_{\Pi}$ or wet snow avalanche pressure $\sigma_{\Phi}^{\mathrm{W}}$. In the runout zone, the standard pressure formula underestimated the pressures required to break trees.

The avalanches in Täsch and Germany consisted of cold snow and were accompanied by large powder clouds. At Täsch the powder cloud was higher than the trees (see Fig. 7). The simulated velocity north of the deflecting dam in the runout zone was $20<u_{\Pi}<30 \mathrm{~m} \mathrm{~s}^{-1}$. We could therefore calculate the bending stresses $\sigma_{\Pi}$ that were exerted by the powder cloud on both the destroyed and surviving larch trees $\left(\rho_{\Pi} \approx 5 \mathrm{~kg} \mathrm{~m}^{-3}\right)$ (Table 4$)$. The effective width $w$ of the trees was small as the larches were leafless. For the destroyed tree (west) we found bending stresses $\sigma_{\Pi}=45 \mathrm{MNm}^{-2}$ (see Fig. 7). For the two surviving trees, middle and east, we found $\sigma_{\Pi}=34 \mathrm{MNm}^{-2}$ and $\sigma_{\Pi}=31 \mathrm{MNm}^{-2}$. In comparison, the dense flowing core exerted pressures $\sigma_{\Phi}^{\mathrm{d}}=18 \mathrm{MNm}^{-2}$ on the destroyed tree and $\sigma_{\Phi}=10 \mathrm{MN} \mathrm{m}^{-2}$ (middle) and $\sigma_{\Phi}=9 \mathrm{MNm}^{-2}$ (east) on the 
two surviving larches (Table 4). Thus, in the runout zone the bending stresses from the powder cloud were larger than the bending stresses produced by the core. This statement remains valid for various release and entrainment scenarios however there is some degree of uncertainty in the model results. This result was duplicated in the German case studies, where the trees were mainly spruce. Bending stresses exerted by the powder cloud were larger than those of the dry core $\sigma_{\Pi}>\sigma_{\Phi}^{\mathrm{d}}$.

For the Monbiel case study, the standard dynamic pressure formula underestimated the forest damage over the entire slope, including the transition and runout zones. We therefore tested the three proposed approaches to calculate the wet snow pressure on the trees: (1) the sliding block model (SBM), $\sigma_{\Phi}^{\mathrm{W}}=41 \mathrm{MN} \mathrm{m}^{-2}$, (2) the creep pressure model (CPM), $\sigma_{\Phi}^{\mathrm{w}}=18 \mathrm{MN} \mathrm{m}^{-2}$ and (3) the standard dynamic approach, $\sigma_{\Phi}^{\mathrm{d}}=3 \mathrm{MN} \mathrm{m}^{-2}$, assuming $c_{\Phi}=1.5$ (Table 4). For the SBM model a volume length of $l_{\mathrm{v}}=20 \mathrm{~m}$ is required to overcome the bending strength of spruces. The opening angle above the trees was taken to be only $\psi=15^{\circ}$. Creep pressures were calculated assuming extreme gliding $(N=3, c=2)$ according to the Swiss guidelines (Margreth, 2007). Pressures exerted by the quasi-static SBM and CPM approaches were in general 1 order of magnitude larger than the pressure calculated with the dynamic approach. Forest damage by the wet snow avalanche in Monbiel could not be simulated with velocity-dependent pressure formulas. Even for $c_{\Phi}=5$, is $\sigma_{\Phi}^{\mathrm{W}}<30 \mathrm{MN} \mathrm{m}^{-2}$ for velocities below $8 \mathrm{~m} \mathrm{~s}^{-1}$. Wet-snow, plug-like avalanches hardly exceed velocities of $u_{\Phi}^{\mathrm{w}}=8 \mathrm{~m} \mathrm{~s}^{-1}$. Our calculations correspond to pressure measurements captured in the Vallee de la Sionne test site (Sovilla et al., 2010, 2014), that could not been explained with dynamic impact formulas.

\section{Conclusions}

To investigate how snow avalanches destroy forests, we developed four flow regime dependent impact formulas. These are powder, intermittent, dry dense and wet dense. The impact formulas were tested on two case studies in Switzerland, Monbiel and Täsch and six avalanches that released in Germany during the winter 2009. The formula parameters (flow velocity, density, height) were obtained from avalanche dynamics calculations and observations. The eight avalanche case studies consisted of seven dry mixed flowing avalanches and one wet snow avalanche. In all cases the forest damage was documented. The standard approach to predict forest damage is to calculate the pressure exerted by the core of a fast moving dry dense avalanche. This case can lead to widespread forest damage; however, it does not explain the damage caused by powder blasts or slow moving wet snow avalanches.

Dry, powder-snow avalanches exert dynamic pressures on the tree stem and the crown. Although the applied impact pressures can be small (less than $3 \mathrm{kPa}$ ), bending stresses in the stem can be large due to the torque action of the blast. The impact pressure, cloud height and impact area must be taken into account to predict forest destruction. Destructive bending stresses can easily be reached even if the density of the snow-air mixture is low. The destructive potential depends on the crown area that is affected by the snow blast and not only on the velocity and density of the powder cloud. The crown area varies with tree position in the forest and on the foliation. Single evergreen trees are exposed to the full avalanche blast and bending stresses are higher in comparison to leafless trees sheltered in clustered forest stands. The presence of deciduous conifer (larch) and broadleaf (birch) tress in an avalanche track is a possible indication of powder snow activity. These tree types can survive powder avalanche blasts because their effective crown areas are small, in contrast to evergreen trees.

The impact pressure formula for the intermittent case was derived by considering individual granule impacts. Interestingly, if we assume a homogeneous velocity and density distribution in the avalanche core, the formula is the same as the standard impact pressure formula used in practice. The density of the flow, however, is considerably smaller in the intermittent case. Therefore, the intermittent case seldom provides pressures higher than the dense case for dry avalanches. However, the intermittent impact formula should be modified to include the effect of particle clusters and uneven velocity distributions. This case could also be modified to include impacts caused by entrained woody debris or rocks. More real examples where these effects could be documented are needed to test a modified formula.

Destructive pressures of wet snow avalanches were backcalculated using two quasi-static modeling approaches, the "sliding block model" (SBM) and the "creep pressure model" (CPM). The results were compared to the standard dynamic approach used for dry snow avalanches. Dynamic models severely underestimated the applied pressures and cannot reproduce the bending stresses required for tree breakage. The sliding block model provided the highest bending stresses and the more realistic results. The creep pressure model underestimated the applied loading in the Monbiel case study. To apply the sliding block model, engineers must estimate the avalanche volume length $l_{\mathrm{v}}$ and the angle $\psi$, which depend on the location of the tree in the forest, terrain and avalanche dimensions. Unlike the dynamic impact loading, the intensity of the wet snow avalanche loading is therefore influenced by the spatial distribution of trees, terrain features and surface roughness. The loading cannot be determined exclusively from the avalanche flow parameters, but requires an understanding of the terrain features upstream of the tree. It is a statically indeterminate problem. Clearly, more case studies are required to validate this approach. However, our initial results suggest that the dynamic pressure can be neglected for large wet snow avalanches flowing with a velocity 
$u_{\Phi}^{\mathrm{w}}<5 \mathrm{~m} \mathrm{~s}^{-1}$. Below this value, static pressures are at least a factor 10 larger than dynamic pressures.

A primary goal of our work is to underscore the importance of field surveys to document forest damage by avalanches. These surveys can provide valuable information on avalanche characteristics and return periods that are needed to formulate hazard scenarios. Broken trees serve as valuable sensors that record avalanche intensity. Our results, however, indicate that impact pressures on trees depend on the avalanche flow regime. For wet snow avalanches, the pressure additionally depends on the distribution of trees in the forest and on terrain features. By differentiating between four different avalanche flow regimes, a more inclusive and reliable analysis of forest damage is possible.

Acknowledgements. This work was funded by the Bavarian Environment Agency. We would especially like to thank Armin Fischer from the Bavarian avalanche service who provided the data of the avalanche events in Bavaria. Leo Jörger and Christian Rüsch from the forest department in Randa and Klosters provided us with valuable information on the forest cover in Monbiel and Täsch and made the field work possible.

Edited by: M. Parise

Reviewed by: three anonymous referees

\section{References}

Baroudi, D., Sovilla, B., and Thibert, E.: Effects of flow regime and sensor geometry on snow avalanche impact-pressure measurements, J. Glaciol., 57, 277-288, 2011.

Bartelt, P. and Stöckli, V.: The influence of tree and branch fracture, overturning and debris on snow avalanche flow, Ann. Glaciol., 32, 209-216, 2001.

Bartelt, P., Feistl, T., Bühler, Y., and Buser, O.: Overcoming the stauchwall: Viscoelastic stress redistribution and the start of fulldepth gliding snow avalanches, Geophys. Res. Lett., 39, L16501, doi:10.1029/2012GL052479, 2012a.

Bartelt, P., Glover, J., Feistl, T., Bühler, Y., and Buser, O.: Formation of levees and en-echelon shear planes during snow avalanche run-out, J. Glaciol., 58, 980-992, 2012b.

Bartelt, P., Buser, O., Bühler, Y., Dreier, L., and Christen, M.: Numerical simulation of snow avalanches: Modelling dilatative processes with cohesion in rapid granular shear flows, in: Numerical Methods in Geotechnical Engineering - Proceedings of the 8th European Conference on Numerical Methods in Geotechnical Engineering, NUMGE, 327-332, 2014.

Bartelt, P., Vera, C., Feistl, T., Christen, M., Bühler, Y., and Buser, O.: A model of cohesion in snow avalanche flow, J. Glaciol., accepted, 2015.

Bebi, P., Kienast, F., and Schönenberger, W.: Assessing structures in mountain forests as a basis for investigating the forests dynamics and protective function, Forest Ecol. Manag., 145, 3-14, 2001.

Bozhinskiy, A. and Losev, K.: The Fundamentals of Avalanche Science, Mitteilungen Eidgenössisches Institut für Schnee- und Lawinenforschung, Davos, 1998.
Bürki, A. F.: Bestandesstrukturen im Gebirgsfichtenwald, PhD thesis, Eidgenösische Technische Hochschule Zürich, Switzerland, 1981 (in German).

Buser, O. and Bartelt, P.: Production and decay of random kinetic energy in granular snow avalanches, J. Glaciol., 55, 3-12, 2009.

Christen, M., Bartelt, P., and Kowalski, J.: Back calculation of the In den Arelen avalanche with RAMMS: interpretation of model results, Ann. Glaciol., 51, 161-168, 2010a.

Christen, M., Kowalski, J., and Bartelt, P.: RAMMS: numerical simulation of dense snow avalanches in three-dimensional terrain, Cold Reg. Sci. Technol., 63, 1-14, 2010b.

Clough, R. W. and Penzien, J.: Dynamics of Structures, Mc GrayHill, Incorporated, 330 West 42nd Street, New York, NY 10036 USA, 1975.

Coutts, M.: Root architecture and tree stability, Plant Soil, 71, 171188, 1983.

de Quervain, M.: Wald und Lawinen, in: Proceedings of the IUFRO Seminar Mountain Forests and Avalanches, Davos, Switzerland, 219-231, 1978.

Dreier, L., Bühler, Y., Steinkogler, W., Feistl, T., and Bartelt, P.: Modelling small and frequent avalanches, in: Proceedings of the International Snow Science Workshop ISSW, Banff, 29 September-3 October 2014, P2.06, 2014.

Faug, T., Naaim, M., and Naaim-Bouvet, F.: Experimental and numerical study of granular flow and fence interaction, Ann Glaciol., 38, 135-138, 2004.

Faug, T., Chanut, B., Beguin, R., Naaim, M., Thibert, E., and Baroudi, D.: A simple analytical model for pressure on obstacles induced by snow avalanches, Ann. Glaciol., 51, 1-8, 2010.

Feistl, T., Bebi, P., Dreier, L., Hanewinkel, M., and Bartelt, P.: Quantification of basal friction for technical and silvicultural glide-snow avalanche mitigation measures, Nat. Hazards Earth Syst. Sci., 14, 2921-2931, doi:10.5194/nhess-14-2921-2014, 2014a.

Feistl, T., Bebi, P., Teich, M., Bühler, Y., Christen, M., Thuro, K., and Bartelt, P.: Observations and modeling of the braking effect of forests on small and medium avalanches, J. Glaciol., 60, 124138, 2014b.

Fischer, J., Kowalski, J., and Pudasaini, S.: Topographic curvature effects in applied avalanche modeling, Cold Reg. Sci. Technol., 74-75, 21-30, 2012.

Geng, J. and Behringer, R. P.: Slow drag in twodimensional granular media, Phys. Rev. E, 71, 011302, doi:10.1103/PhysRevE.71.011302, 2005.

Götz, K.: Die innere Optimierung der Bäume als Vorbild für technische Faserverbunde - eine lokale Approximation, Forschungszentrum Karlsruhe, Germany, 2000 (in German).

Gray, J., Tai, Y. C., and Noelle, S.: Shock waves, dead zones and particle-free regions in rapid granular free-surface flows, J. Fluid Mech., 491, 161-181, 2003.

Grosser, D. and Teetz, W.: Einheimische Nutzhölzer, Centrale Marketinggesellschaft der deutschen Agrarwirtschaft GmbH (CMA), Bonn, und Arbeitsgemeinschaft Holz e.V., Düsseldorf, Germany, 1985 (in German).

Häfeli, R.: Kriechen und progressiver Bruch in Schnee, Boden, Fels und Eis, Schweizerische Bauzeitung, 85, 1-9, 1967 (in German).

Hauksson, S., Pagliardi, M., Barbolini, M., and Johannesson, T.: Laboratory measurements of impact forces of supercritical gran- 
ular flow against mast-like obstacles, Cold Reg. Sci. Technol., 49, 54-63, 2007.

In der Gand, H. and Zupančič, M.: Snow gliding and avalanches, IAHS-AISH Publ., 69, 230-242, 1966.

Indermühle, M.: Struktur-, Alters- und Zuwachsuntersuchungen in einem Fichten-Plenterwald der subalpinen Stufe, PhD thesis, Eidgenössische technische Hochschule Zürich, Switzerland, 1978 (in German).

Johannesson, T., Gauer, P., Issler, P., and Lied, K.: The design of avalanche protection dams, in: Recent Practical and Theoretical Developments, European Commission, Chap. 12, 95-107, European Commission, Office CDMA 3/120, B-1049 Brussels, Belgium, 2009.

Johnson, E. A.: The relative importance of snow avalanche disturbance and thinning on canopy plant populations, Ecology, 68, 43-53, 1987.

Jonsson, M., Foetzki, A., Kalberer, M., Lundström, T., Ammann, W., and Stöckli, V.: Root-soil rotation stiffness of norway spruce (Picea Abies (1.) karst) growing on subalpine forested slopes, Plant Soil, 285, 267-277, 2006.

Lang, T. E. and Brown, R. L.: Snow avalanche impact on structures, J. Glaciol., 25, 445-455, 1980.

Lavers, G. M.: The strength properties of timber, Building Research Establishment Report, 3rd Edn., Her Majesty's Stationery Office, London, 1983.

Lundström, T., Jonsson, M. J., Volkwein, A., and Stoffel, M.: Reactions and energy absorption of trees subject to rockfall: a detailed assessment using a new experimental method, Tree Physiol., 29, 345-359, 2009.

Margreth, S.: Lawinenverbau im Anbruchgebiet, Technische Richtlinie als Vollzugshilfe, Bundesamt für Umwelt, Bern, Switzerland, 2007 (in German).

Mattheck, C. and Breloer, H.: Handbuch der Schadenskunde von Bäumen: Der Baumbruch in Mechanik und Rechtsprechung, Freiburg im Breisgau: Rombach, 1994 (in German).

Mayhead, G.: Some drag coefficients for british forest trees derived from wind tunnel studies, Agr. Meteorol., 12, 123-130, 1973.

McClung, D. and Schaerer, P.: Characteristics of flowing snow and avalanche impact pressures, Ann. Glaciol., 6, 9-14, 1985.

Naaim, M., Naaim-Bouvet, F., Faug, T., and Bouchet, A.: Dense snow avalanche modeling: flow, erosion, deposition and obstacle effects, Cold Reg. Sci. Technol., 39, 193-204, 2004.

Naaim, M., Faug, T., Thibert, E., Eckert, N., Chambon, G., Naaim, F., and Bellot, H.: Snow avalanche pressure on obstacles, in: Proceedings of the International Snow Science Workshop, Whistler, Canada, 21-27 September 2008, ID: P_8119, 2008.

Norem, H.: Estimating snow avalanche pressures on towers, in: Proceedings of a Workshop on Avalanche Dynamics, 14-18 May 1990, 1991.

Pedersen, R., Dent, J., and Lang, T.: Forces on structures impacted and enveloped by avalanches, J. Glaciol., 22, 529-534, 1979.

Peltola, H. and Kellomäki, S.: A mechanistic model for calculating windthrow and stem breakage of scots pines at stand age, Silva Fenn., 24-31, 1993.

Peltola, H., Nykänen, M. L., and Kellomäki, S.: Model computations on the critical combination of snow loading and windspeed for snow damage of scots pine, norway spruce and birch sp. at stand edge, Forest Ecol. Manag., 95, 229-241, 1997.
Peltola, H., Kellomäki, S., Väisänen, H., and Ikonen, V. P.: A mechanistic model for assessing the risk of wind and snow damage to single trees and stands of scots pine, norway spruce, and birch, Can. J. Forest Res., 29, 647-661, 1999.

Peltola, H., Kellomäki, S., Hassinen, A., and Granander, M.: Mechanical stability of scots pine, norway spruce and birch: an analysis of tree-pulling experiments in finland, Forest Ecol. Manag., 135, 143-153, 2000.

Pretzsch, H.: Canopy space filling and tree crown morphology in mixed-species stands compared with monocultures, Forest Ecol. Manag., 327, 251-264, 2014.

Salm, B.: Snow forces on forest plants, in: Mountain Forests and Avalanches, Swiss Federal Institute for Snow and Avalanche Research, 7260 Davos, Switzerland, 157-181, 1978.

Salm, B., Burkard, A., and Gubler, H.: Berechnung von Fliesslawinen: eine Anleitung für Praktiker mit Beispielen, Eidgenössisches Institut für Schnee- und Lawinenforschung, SFISAR; EDMZ, Berne, 1979, 1990 (in German).

Sheikh, A. H., Verma, S. C., and Kumar, A.: Interaction of retarding structures with simulated avalanches in snow chute, Curr. Sci India, 94, 916-921, 2008.

Sovilla, B., Kern, M., and Schär, M.: Slow drag in wet-snow avalanche flow, J. Glaciol., 56, 587-592, 2010.

Sovilla, B., Sonatore, I., Bühler, Y., and Margreth, S.: Wet-snow avalanche interaction with a deflecting dam: field observations and numerical simulations in a case study, Nat. Hazards Earth Syst. Sci., 12, 1407-1423, doi:10.5194/nhess-12-14072012, 2012.

Sovilla, B., Margreth, S., Schaer, M., Thiebert, E., Fischer, J. T., Baroudi, D., and Ancey, C.: Taking into account wet avalanche load for the design of tower-like structures, in: Proceedings of the International Snow Science Workshop ISSW, 29 September3 October 2014, Banff, 2014.

Stokes, A., Salin, F., Kokutse, A. D., Berthier, S., Jeannin, H., Mochan, S., Dorren, L., Kokutse, N., Ghani, M. A., and Fourcaud, T.: Mechanical resistance of different tree species to rockfall in the french alps, Plant Soil, 278, 107-117, 2005.

Teich, M., Bartelt, P., Grêt-Regamey, A., and Bebi, P.: Snow avalanches in forested terrain: influence of forest parameters, topography and avalanche characteristics on runout distance, Arct. Antarct. Alp. Res., 44, 509-519, 2012.

Teich, M., Fischer, J.-T., Feistl, T., Bebi, P., Christen, M., and Grêt-Regamey, A.: Computational snow avalanche simulation in forested terrain, Nat. Hazards Earth Syst. Sci., 14, 2233-2248, doi:10.5194/nhess-14-2233-2014, 2014.

Teufelsbauer, H., Wang, Y., Pudasaini, S., Borja, R., and Wu, W.: Dem simulation of impact force exerted by granular flow on rigid structures, Acta Geotech. Slov., 6, 119-133, 2011.

Vera, C., Wikstroem, K., Bühler, Y., and Bartelt, P.: Release temperature, snowcover entrainment and the thermal flow regime of snow avalanches, J. Glaciol., 61, 173-184, doi:10.3189/2015JoG14J117, 2015. 